\title{
ZAŠTO NE ESTETIKA IGRE? **
}

Ovaj rad posvećen je razmatranju estetike igre, shvaćene kao filozofije umetnosti plesa. U radu se razmatraju uzroci činjenice da umetnost igre, za razliku od drugih umetnosti, nikada nije predstavljala jednu od centralnih tema filozofskog istraživanja; cilj rada je da podrobnije predstavi i osvetli ove uzroke. Ponuđene analize orijentisane su na rađanje modernog pojma lepih umetnosti u XVIII veku i formiranje kategorizacije pet kardinalnih umetnosti: metod rada sastoji se $u$ hermeneutičkom razvijanju i poređenju različitih određenja pojma umetnosti i posledičnom razumevanju statusa igre. Rezultati izvedeni na osnovu ovih analiza pokazuju da je izostajanje igre iz korpusa kardinalnih umetnosti u novovekovnom promišljanju umetnosti posledica primata problema saznanja u kontekstu određivanja smisla i funkcije umetnosti uopšte. Zaključak rada predstavlja stav da bi savremena estetika morala da nadomesti ovaj izostanak estetike igre, te da razmatranje uzroka njenog izostanka u tradiciji buduća istraživanja može postaviti na adekvatne temelje.

Ključne reči: filozofija, estetika igre, umetnost, balet, saznanje.

Estetika predstavlja jednu od istorijski najmlađih filozofskih disciplina: ona nastaje tek u XVIII veku, a njen naziv i zasebni disciplinarni smisao uspostavlja A. G. Baumgarten (A. G. Baumgarten). Istorija filozofije, svakako, i pre Baumgartena poznaje razmatranja posvećena lepoti i umetnosti, pa delimično i ona posvećena estetskom iskustvu, no tek Baumgarten ova tri problemska područja postavlja kao integralni problem, odnosno tek sa Baumgartenovom estetikom filozofska misao započinje sa istraživanjem sistemske povezanosti ovih tema (Zurovac, 2016: 384385). Razvoj estetike nakon Baumgartena, međutim, bio je jednako neobičan: njegov projekat je, čini se, u svom duhu usvojen, no njegov smisao iznova i iznova je reinterpretiran, te je tako estetika zadobijala najrazličitije oblike i uloge. $U$ razvoju discipline nakon Baumgartena može se naročito primetiti tendencija postepenog izdvajanja umetnosti kao centralnog problema estetičkih razmatranja: još od Šelinga (F. W. J. Schelling), Šilera (F. Schiller) i Hegela (G. W. F. Hegel) umetnost postaje naglašeni fenomen i problem estetike. Navedena tendencija

\footnotetext{
*unapopovic@ff.uns.ac.rs

** Ovaj rad nastao je zahvaljujući podršci Republičkog ministarstva prosvete, nauke i tehnološkog razvoja tokom rada na projektu 179007.
} 
direktno je suprotstavljena tradiciji filozofskog istraživanja naznačenih estetičkih problema, budući da je njom dominirao problem lepote, posebno istaknut na fenomenu lepote prirodnih bića.

Naglašeni interes za problem umetnosti posebno se očituje u XX veku, što je u velikoj meri provocirano načinom na koji se razvijala i sama umetnost, odnosno nizom umetničkih pravaca i pokreta koji su bitno doveli u pitanje filozofski pojmovni aparat kojim se prethodno tumačio smisao i suština umetničkih dela. Pri tome su, čini se, tradicionalna teorija umetnosti kao podražavanja, kao i teza o umetnosti kao proizvođenju lepote, doživele najsnažniji otpor i kritiku: za umetnost savremenog doba teško je pronaći odgovarajuću reč, ali je, podjednako, skoro nemoguće takvu reč pronaći u filozofskom pojmovniku tradicije.

Savremeni razvoj umetnosti, međutim, u odnosu na filozofsko promišljanje umetnosti imao je još jednu značajnu posledicu. Naime, tradicionalno se filozofija umetnošću bavila kao integralnim fenomenom, obuhvatajući pod pojmom umetnosti različite njene oblike i žanrove. Doduše, ovakvo razumevanje umetnosti u punom smislu važi tek od modernog doba, kada je i oformljen pojam lepih umetnosti i klasična klasifikacija kardinalnih umetnosti; doba antike, srednjevekovlja i renesanse umetnost razumeva u nešto širem kontekstu, koji pored umetničkih dela zahvata i zanate, kao i nauke. Klasična klasifikacija umetnosti, koja obuhvata slikarstvo, vajarstvo, poeziju, muziku i igru, pripisuje se Šarlu Bateu (Charles Batteux) - autoru koji je 1747. godine uveo pojam lepih umetnosti, odnosno ideju da suština umetnosti nije podražavanje, već proizvođenje lepote (Tatarkijevič, 1980: 16-17). Svakako, ova klasična klasifikacija mnogo je puta proširivana i revidirana, $u$ čemu je pojava novih medija - fotografije i filma - imala odlučujući značaj.

Ipak, u horizontu razvoja savremene umetnosti, ovakvo razumevanje njenog pojma, čini se, postaje isuviše usko i određeno. Teorijski pristupiti analizi umetnosti podrazumevajući suštinski ili supstancijalni identitet, na primer, Pikasovih dela i formacija umetnika Lendarta (Land art) već na prvi pogled deluje nemoguće. Napokon, i sama umetnost XX veka jasno izražava pretenziju na autonomiju i samoodređenje, čak i u teorijskom kontekstu, čime se otvara još jedna od gorućih tema savremene estetike - pitanje o legitimnosti filozofskog istraživanja umetnosti, odnosno o adekvatnom filozofskom pristupu analizi umetničkih projekata i dela. U okvirima same filozofije, stoga, svedočimo svojevrsnoj dezintegraciji sistemskog projekta zahvatanja celine ili suštine svih umetnosti, te se u filozofskoj misli XX veka sve češće javljaju teorije koje tumače neku od umetnosti zasebno, bez pretenzije na celinu njene fenomenske datosti. 
Drugim rečima, već početkom XX veka filozofi se okreću uže fokusiranim analizama književnosti, poezije, slikarstva i muzike, neretko zanemarujući i napuštajući ideju lepih umetnosti. Fenomenološka škola, primera radi, nudi zanimljive primere zasebnih razmatranja različitih umetnosti, sprovedenih na pozadini jedinstvenog fenomenološkog metoda, ali ipak razdvojenih u zasebne studije; takve primere nude nam Estetika Nikolaja Hartmana (N. Hartmann), kao i Ontologija umetnosti Romana Ingardena (R. Ingarden). Književnost i poezija sa jedne, a slikarstvo i uopšte vizuelne umetnosti sa druge strane imaju odlikovano mesto u ovakvim razmatranjima, dok se pitanje muzike postupno i sve više profiliše počev od formalizma Eduarda Hanslika (E. Hanslick), a naročito u misli Teodora V. Adorna (T. W. Adorno).

Ipak, uprkos tome što predstavlja jednu od umetnosti navedenih u Bateovoj klasifikaciji lepih umetnosti, te uprkos tome što se kao umetnost naročito razvija krajem XIX i početkom XX veka, igra - pre svega, balet - skoro da posve izostaje iz filozofskih spisa ovog doba (Lippincott, 1949: 97-98). Odustvo jedne filozofije ili estetike igre utoliko je zanimljivije što se, kako smo već naveli, period naglašenog razvoja ove umetnosti poklapa sa periodom naglašene diversifikacije filozofskih tumačenja umetnosti. Mi danas ne samo da nemamo filozofsku tradiciju estetike igre, kao osobene filozofije umetnosti, već retko možemo pronaći komentare posvećene igri čak i u onim filozofijama koje igru zahvataju u kontekstu drugih umetnosti, najčešće muzike ili teatra. Tim povodom Frensis Sparšot (F. Sparshott), jedan od filozofa koji su u najvećoj meri skrenuli pažnju na ovaj problem, kaže sledeće: „estetika poslednja dva veka jednako zanemaruje ples; i [...] da neke varijante osamnaestovekovnih sistema lepih umetnosti nisu samo nedovoljno naglasile umetnost igre, već su je zapravo u potpunosti isključile iz razmatranja” [prev. U.P.] (Sparshott, 1983: 164).

Estetika igre, dakle, predstavlja centralnu okosnicu našeg istraživanja. Njoj, međutim, iz navedenih razloga ne možemo pristupiti neposredno: kako je već naglašeno, reč je pre o odsustvu nego o dominaciji estetike igre. Upravo ovo odsustvo predstavlja naš osnovni interes: u radu ćemo, bar delimično, pokušati da osvetlimo razloge usled kojih se ono javlja.

\section{ODSUSTVO ESTETIKE IGRE}

Pristupajući istraživanju odsustva estetike igre, najpre moramo razlučiti šta se u ovom kontekstu podrazumeva pod pojmom igre. Pojam igre, naime, ima svoje mesto, pa čak i značajnu ulogu u tradiciji filozofije; neretko se on nalazi čak i u estetičkim teorijama, poput Kantove (I. Kant) ili Šilerove. Ipak, ovako shvaćen 
pojam igre $\mathrm{u}$ istoriji filozofije nije neposredno vezan za igru kao jednu od umetnosti, niti njegovo prominentno mesto u okvirima neke estetike garantuje da će se $\mathrm{u}$ istim okvirima naći i analize umetnosti igre, kako to pokazuju i estetička razmatranja pomenutih Kanta i Šilera. Stoga, kada govorimo o odsustvu estetike igre, ne smeramo na sam pojam igre i njegovu filozofsku povest, već ciljamo upravo na umetnost igre i nedostatak filozofskih razmatranja koja bi njoj bila posvećena.

Sa druge strane, u ovom istraživanju opredelili smo se za pojam estetike igre, a ne estetike plesa; u svakodnevnoj jezičkoj upotrebi ova dva pojma mogu se razumeti kao sinonimi, a u pogledu filozofske terminologije na našim prostorima još uvek ne postoji standardizovana terminologija koja bi nas uslovila da se pridržavamo jednog od ova dva rešenja. ${ }^{1}$ Kao što je već navedeno, pod estetikom igre pre svega ciljamo na filozofska razmatranja igre kao jedne od umetnosti: u horizontu našeg prethodnog razlikovanja estetike igre spram smisla koji bi se, na primer, mogao pripisati Šileru ili nekim drugim autorima, ovo opredeljenje može biti shvaćeno kao nedovoljno precizno. Ipak, za pojam estetike igre odlučujemo se zbog uverenja da postoji važna veza između pojma igre u široj filozofskoj i estetičkoj upotrebi sa jedne, te umetnosti igre i njenog prisustva/izostajanja unutar filozofskih razmatranja sa druge strane. Pomenuta veza, smatramo, ne može biti podrobnije rasvetljena u okvirima ovog istraživanja, prevashodno zbog toga što bi njena tematizacija zahtevala posve drugačije ustrojen rad, a potom i zbog toga što smatramo da njeno detaljnije izvođenje mora biti pripremljeno razmatranjem položaja i statusa igre kao umetnosti u tradiciji filozofije.

Međutim, ukoliko pojam igre želimo da rezervišemo za užu sferu umetnosti plesa i pokreta, a ne za načelni pojam igre, kakav češće možemo pronaći u tradiciji filozofije i estetike, čini se da smo najpre upućeni na umetnost baleta (Sparshott, 1983: 180). Preciznije rečeno, ukoliko bismo pratili načelne gestove tradicije estetike ne samo u pogledu na igru, već i u pogledu na ostale umetnosti, moramo primetiti da je, bar u moderno doba, teorijski interes skoro isključivo bio usmeren na visoko profilisanu umetnost, kakva je uvažavana od strane viših slojeva društva. Drugim rečima, moderna estetika ne bavi se narodnom i folklornom umetnošću, već, slobodnije rečeno, umetnošću dobrog ukusa - umetnošću građanskog društva.

\footnotetext{
${ }^{1}$ Delimičnu naznaku u tom smeru nudi nam terminološko rešenje samih umetnika, koji su, bar na našoj javnoj sceni, stali uz pojam igre, a ne plesa. Tako je upravo pojam igre odabran kao centralni pojam naziva prestižnog Beogradskog festivala igre, koji se održava već petnaest godina. Ova naznaka, svakako, ne uslovljava filozofsko razmatranje, ali ipak može biti indikativna za njega.
} 
Ukoliko u tim okvirima očekujemo jednu filozofiju igre, nju bismo onda najpre morali tražiti kao orijentisanu na balet.

Ipak, za savremeno društvo i misao takvo ograničenje teško da bi bilo prihvatljivo, budući da je i sama umetnost igre uveliko razvila oblike neklasične za takozvani beli balet, te danas uključuje najrazličitije međuforme i preplitanja igračkih poetika. U tom smislu i mi smo se u ovom radu odlučili za širi pojam igre, odnosno estetike igre - a ne za pojam baleta ili estetike baleta. Alternativni pojam filozofije igre $\mathrm{u}$ ovom kontekstu uputio bi na pomenuti smisao pojma igre $\mathrm{u}$ vanestetičkim filozofskim kontekstima - ili u estetičkim kontekstima koji nisu neposredno vezani za ples, dok bi pojam estetike baleta bio preuzak za naše potrebe. Odsustvo estetike igre, dakle, podrazumeva činjenicu da u estetikama modernog i savremenog doba umetnost igre retko ili skoro nikad ne predstavlja predmet filozofske refleksije.

Ovo odsustvo estetike igre - bilo u razvijenom, bilo u rudimentarnom obliku - interesantno je iz niza razloga. Možda najinteresantniji od njih, kako navodi i Sparšot, predstavlja činjenica da igra $u$ našoj civilizaciji nesumnjivo predstavlja jednu od umetnosti, odnosno da njen status umetnosti nije problematičan; povrh toga, kako smo videli, čini se da filozofija u širem smislu uvažava igru i pripisuje joj odlikovan značaj (Sparshott, 1983: 165). Uprkos tome, odlikovani status igre kao umetnosti, koji smo već pomenuli u vezi sa Bateovom klasičnom listom umetnosti, izgubljen je već tokom XVIII veka: iako se igra zaista nalazi na Bateovoj listi, ona ubrzo svoje mesto ustupa arhitekturi, te se tako osamnaestovekovno poimanje umetnosti orijentiše spram sledećih pet kardinalnih umetnosti: slikarstva, vajarstva, arhitekture, muzike i poezije (Kristeller, 1951: 497).

Ipak, iako nije održala svoj status jedne od kardinalnih umetnosti modernog doba, te shodno tome nije zadobila ni sebi adekvatnu estetiku, igra je ipak svoj teorijski status ponekad ostvarivala posredno. Drugim rečima, status igre u razmatranjima umetnosti često je bio povezan sa drugim, teorijski više priznatim oblicima umetnosti - kako smo naveli, pre svega sa muzikom i teatrom. U oba slučaja ova tendencija svoje poreklo vodi od antičkog razumevanja umetnosti kao poiesis-a - kompleksnog pojma koji je integralno označavao za nas razdvojene umetnosti drame (poezija u užem smislu), teatra, igre i muzike - te tako ona donekle predstavlja reziduum antičke tradicije razumevanja umetnosti. Sa druge strane, može se reći da je upravo ova tendencija dugo vremena zakrivala potrebu da se o igri misli i govori kao o zasebnoj umetnosti, nezavisno od teatra ili muzike.

Potonja zakrivenost igre perspektivom teatra donekle je razumljiva: budući da se igra tradicionalno i odvija na teatarskoj sceni, te da je često predstavljala 
integralni deo teatarskih postavki, igra je mogla imati status sličan onom koji ima scenografija - status dodatne opreme, pozadine koja omogućava da se ono istinski umetničko (dramsko) u punoj meri manifestuje (Sparshott, 1982: 5; Caroll, 1992: 322). Važno je, međutim, primetiti da primat teatra u odnosu na igru u ovom kontekstu ne donosi mnogo toga estetici igre: igra i u ovim slučajevima izostaje iz teorijskog fokusa, budući da je teatar, jednako kao igra, izostavljen iz osamnaestovekovnog popisa kardinalnih umetnosti, a time i suštinski zanemaren sve do XX veka. ${ }^{2}$

Sličnu sudbinu igra deli i kada je reč o njenoj vezi sa muzikom. Naime, veoma često igra se razumevala kao neposredna posledica muzike, kao neka vrsta njenog (telesnog) produžetka. Svakako, ključni pojmovi koji obezbeđuju teorijsku vezu između dve umetnosti su ritam i harmonija - pojmovi koji bar za antičku misao imaju specifičnu višeznačnu upotrebu, povezanu kako sa pitanjem obrazloženja lepote, tako i sa problemima zahvatanja metafizičkih osnova stvarnosti. Međutim, u istoriji filozofije muzika je imala nešto drugačiji tretman od teatra: muzika je dugo teorijski razmatrana kao jedna od matematičkih nauka - kao deo srednjevekovnog quadrivium-a, na primer - odnosno njen se teorijski status sve do modernog doba koleba između uže estetičke i naučne pozicije. Osvit uže estetičke filozofije muzike, međutim, na Kantovom tragu nastaje u okvirima Hanslikovog formalizma, koji, pak, iz razmatranja muzike načelno isključuje sve vanmuzičke faktore. U tom horizontu, jasno je, nema mnogo mesta ni za igru.

Analiza odsustva estetike igre, prema našem mišljenju, mora uvažiti ovaj kontekst preplitanja, odnosno nedovoljno jasno sprovedene diferencijacije između pojedinih umetnosti. Pri tome ne želimo reći da zapadna kultura i misao ne razlikuje igru od, na primer, muzike; pre se radi o tome da se u moderno doba - doba naglašenog interesa za estetička pitanja, doba zasnivanja estetike - pojedine umetnosti ističu kao predmet filozofskog interesa, dok druge ostaju van takvog fokusa. Drugim rečima, uzroke odsustva estetike igre, čini se, moramo tražiti u samom osvitu modernog razumevanja (lepih) umetnosti, budući da upravo tada na scenu stupa osobena dijalektika uključivanja/isključivanja pojedinih umetnosti, odnosno teorijskog odabira i valorizovanja sprovedenog unutar korpusa postojećih umetnosti. Ovakvo razlikovanje naglašeno ostavlja igru na margini horizonta estetike, a posledice toga evidentne su i u savremeno doba.

2 Teatar je estetički bio obrađivan u kontekstu modela poetike, svakako pod velikim uticajem Aristotela. Međutim, poetička razmatranja u kulturi modernog doba prevashodno su fokusirana na poeziju i književnost, odnosno na uže literarni kontekst drame. 


\section{ZAŠTO NE ESTETIKA IGRE?}

Razlozi koje možemo navesti kao objašnjenja za ovako ocrtano odustvo estetike igre i interesa za nju mnogobrojni su: $u$ relativno skorašnjoj literaturi vezanoj za ovu problematiku možemo pronaći nekoliko osnovnih tendencija.

Jedno od klasičnih objašnjenja ovog odsustva estetike igre suštinski je hegelijanski inspirisano. Naime, pojedini autori tvrde da je igra izostala iz fokusa filozofskih razmatranja zbog toga što ovaj oblik umetnosti nikada nije bio izraz centralnih duhovnih tendencija nekog od evropskih društava (Burt, 2006: 188; Sparshott, 1982: 6-7). U tom smislu primat književnosti ili slikarstva objašnjava se tezom da ove umetnosti jesu u svoje vreme imale osobenu kulturnu, ako ne i kultnu ulogu, odnosno tezom da su one predstavljale svojevrsni konstituens samorazumevanja društva. Umetnosti poput igre, koje nikada nisu imale takvu ulogu, posledično izlaze iz fokusa filozofije kao teorijske refleksije o samorazumevanju čoveka i društva.

Nešto savremenije reakcije odsustvo estetike igre objašnjavaju pozivanjem na patrijarhalni model evropske kulture, koja ono telesno i senziblino vezuje za ženski princip (Lippincott, 1949: 100-101). Ova teza može se primeniti jednako na tradiciju, kao i na savremenost estetike, a u pogledu tradicije ona se jednako može dovesti u vezu i sa opštim stavom da je estetsko iskustvo - a samim tim i iskustvo umetnosti - suštinski iracionalno, te time i manje vredno. Ipak, čini se da su ovakvi pristupi donekle jednostrani: sam Sparšot nizom argumenata pobija tezu o ženskoj prirodi igre kao razlogu izostajanja njenog teorijskog razmatranja (Sparshott, 1982: 9-10). Dodatno, nema osnova da se argument iracionalnosti primeni naročito ili isključivo na igru: ukoliko bismo pristali na ovaj argument, onda bismo morali očekivati da je evropska misao suštinski bila nezainteresovana za sve oblike umetnosti, što izvesno nije slučaj.

Ipak, teza o iracionalnom karakteru umetnosti može donekle poslužiti za razumevanje odsustva igre. Naime, ovde je potrebno ponovno osvetliti već pomenutu kategorizaciju klasičnih pet umetnosti, ovaj put ne toliko s obzirom na činjenicu da se unutar nje igra pojavljuje i iščezava, koliko s obzirom na činjenicu da ovakva lista podrazumeva svojevrsni odabir unutar umetnosti. Drugim rečima, ovde nije reč o tome da igra ili teatar, budući da nisu uvršteni u listu, ne predstavljaju umetnosti: kao što je već naglašeno, njihov status umetnosti nikada nije doveden u pitanje. Shodno tome, postavlja se pitanje zbog čega se onda vrši izbor između već priznatih umetnosti - zbog čega nisu sve uključene u listu?

Poređenja radi, potonje kontroverze povodom statusa fotografije i filma kao umetnosti razumljive su: osamnaesti vek izvesno nije poznavao ni fotografiju ni 
film, te ih stoga nije ni mogao uključiti u osnovnu kategorizaciju. Kada su fotografija i film izumljeni, njihovo uključivanje u korpus umetnosti bilo je problematično usled činjenice da su kako produkcija, tako i recepcija ovih umetnosti radikalno različite od onih klasičnih: priznavanje statusa umetnosti fotografiji i filmu podrazumevalo je i revidiranje smisla samog pojma umetnosti. Međutim, slučaj igre ili teatra nije takav: ove umetnosti postojale su i bile priznate kao umetnosti i u XVIII veku, a ipak nisu bile uključene u osnovni spisak.

Stoga, ukoliko se u razmatranju vodimo pitanjem inkluzije/ekskluzije pojedinih umetnosti iz korpusa kardinalnih umetnosti, problem možemo sagledati iz perspektive kriterijuma na osnovu kog je inkluzija/ekskluzija i ostvarena. Ovde se iznova susrećemo sa problemom iracionalnog karaktera umetnosti: klasični odabir umetnosti je, čini se, vođen pitanjem mogućeg doprinosa pojedinih umetnosti procesu saznanja. Primer takve prakse možemo pronaći u prosvetiteljskoj misli - u Dalamberovom uvodu za Enciklopediju čitamo: „Postoji druga vrsta refleksivnih saznanja o kojima treba sada da govorimo: ona se sastoje iz ideja koje mi obrazujemo, zamišljajući i stvarajući bića slična onima koja su predmet naših neposrednih ideja: to je ono što se zove imitacija prirode" (Dalamber, 1955: 21). A odmah potom čitamo i sledeće: „Na čelo saznanja koja se sastoje u imitiranju treba da budu stavljeni Slikarstvo i Skulptura, zato što se u njima više nego u svim ostalim imitiranje približava predmetima koje predstavlja i najposrednije govori čulima" (Dalamber, 1955: 22). Na istom mestu dalje Dalamber navodi i ostale tri kardinalne umetnosti - arhitekturu, poeziju i muziku, ali ne i igru.

Stav enciklopedista potpuno je jasan: umetnosti su predstavljene kao svojevrsni vid saznanja stvarnosti, a izbor unutar njih - pa čak i osobena vrednosna hijerarhija - ostvareni su s obzirom na pitanje u kojoj meri umetnosti doprinose saznanju. Ovaj izbor i vrednovanje umetnosti, dakle, nisu sprovedeni s obzirom na njihov imanentno estetski karakter, iako bi enciklopedisti nesumnjivo tvrdili da saznajni i podražavalački karakter umetnosti jeste suština onog estetskog. U tako postavljenoj sistematici igra nema prominentno mesto; otuda možemo zaključiti da ona, iako umetnost, ne zadovoljava minimum kriterijuma doprinosa saznanju stvarnosti koji bi je učinio značajnim za prosvetiteljski projekat.

U poređenju sa tim, Šarl Bate, koji uključuje igru u osnovni korpus umetnosti, kao kriterijum razlikovanja lepih od ostalih umetnosti ne izdvaja pitanje saznanja, već podražavanje lepe prirode. Ovde je na delu osobeno prevrednovanje tradicionalne definicije umetnosti kao podražavanja: Bateovo razumevanje ide korak dalje od toga, te proglašava proizvođenje lepote za suštinu umetnosti, ali je ovaj preobražaj suštine umetnosti izveden uz pomoć inkorporiranja pojma podražavanja. Naime, za razliku od ostalih podražavalačkih delatnosti, lepe 
umetnosti ne podražavaju prirodu - već lepu prirodu (belle nature) (Batteux, 2015: 12-13). Drugim rečima, suština umetnosti nije usmerena na zahvatanje prirode kakva je data za saznajni aparat, već umetnost treba da na videlo iznese upravo onaj aspekt prirode koji se, bar za mislioce XVIII veka, bitno opire potpunom saznanju.

Ne ulazeći detaljno u razmatranje Bateovog pojma lepe prirode, što bi zahtevalo naročitu razradu budući da se radi o centralnom i vrlo kompleksnom pojmu njegove filozofije, ipak možemo zaključiti da je centralna razlika Bateovog i Dalamberovog pristupa upravo u uključivanju - odnosno izostavljanju perspektive saznanja u kriterijum odabira kardinalnih umetnosti. Koliko je ovo razlikovanje značajno, svedoči i činjenica da se najznačajniji teoretičar baleta XVIII veka, Nover (J. G. Noverre), argumentišući u prilog razumevanju baleta kao autonomne umetnosti pozivao upravo na Batea, tvrdeći da je balet jedna od tri umetnosti koje podražavaju lepu prirodu (Sparshott, 1982: 9). Ugledajući se na Batea, Nover preuzima pojam podražavanja u novom ključu, ali ga primenjuje osobeno na problem igre: $\mathrm{u}$ ovom kontekstu veza lepote i prirode putem podražavanja biva naročito naglašena, budući da je upotrebljena kao argument $u$ korist ekspresivne igre, a protiv igre kao praćenja unapred zadatih formi pokreta (Chazin-Bennahum, 2007: 95).

Drugim rečima, čini se da dva navedena primera jasno pokazuju da je upravo saznajni karakter, odnosno doprinos estetskog iskustva umetnosti saznajnom procesu sporno mesto na kom se lomi pitanje igre kao jedne od kardinalnih umetnosti. Kako umesno kaže Lipinkotova (G. Lippincott), čini se da filozofi ne smatraju da je igra dovoljno apstraktna da bi postala predmetom njihovih proučavanja (Lippincott, 1949: 102). Istovremeno, teorije i estetike XVIII veka koje viziraju igru bitno su usmerene ka sagledavanju imanentnih odlika umetnosti, njenih uže estetskih svojstava $\mathrm{i}$ aspekata, te zaobilaze tradicionalni platonički problem odnosa umetnosti i istine.

\section{ZAKLJUČNA RAZMATRANJA}

Odsustvo estetike igre, koje smo razmatrali u prethodnim analizama, čini se da sugeriše veoma poseban status ove umetnosti. Naime, njeno isključenje iz korpusa kardinalnih umetnosti s obzirom na kriterijum saznanja - odnosno njeno uključivanje $\mathrm{u}$ isti korpus $\mathrm{s}$ obzirom na kriterijum podražavanja lepe prirode, naznačavaju da je u pitanju umetnost koja se bitno opire tradicionalnom načinu mišljenja karakterističnom za estetička razmatranja. Otuda se čini da igra, ukoliko se zahteva njena filozofska obrada, zahteva nov i netradicionalan estetički pristup takav koji bi fokusirao imanentno estetske odlike svog predmeta, zanemarujući 
vanestetičke filozofske interese. Ova mogućnost bitno je otvorena tendencijama estetičkih razmatranja modernog doba, koja u krajnjem vode i zasnivanju estetike kao filozofske discipline; problem umetnosti u tim okvirima, iako još uvek nije jedan od vodećih, jasno pokazuje unutrašnje napetosti i preobraženja nove estetske senzibilnosti Evrope.

Značaj određivanja korpusa kardinalnih umetnosti, koji smo više puta isticali, zapravo je uslovljen činjenicom da doba XVII i XVIII veka predstavlja doba rađanja modernog pojma umetnosti, kakav je i danas u velikoj meri na snazi. Naime, usled razvoja moderne ideje nauke, kao osobenog teorijskog poduhvata različitog od filozofije, pojam umetnosti bitno se sužava u odnosu na pređašnje konotacije, vezane za nauke i veštine (Kristeller, 1951: 526). Drugim rečima, u moderno doba pojmovi umetnosti i nauke po prvi put se striktno razdvajaju, a to podrazumeva i nov način razumevanja smisla umetnosti (Zurovac, 2016: 254-255). Kako smo videli, ova promena jasno je markirana stvaranjem pojma lepih umetnosti; no ona je podrazumevala i otvaranje mogućnosti da se o umetnostima misli ne polazeći od perspektive saznanja (model nauka), već polazeći od njenih uže estetskih aspekata. Napokon, takva promena uslovila je i potrebu za preciznijim razgraničenjem pojma umetnosti u pogledu njegovog domena, što je rezultovalo formiranjem ideje korpusa kardinalnih umetnosti.

Kako smo videli, umetnost igre u ovim okvirima deli sudbinu razvoja samog pojma umetnosti: ona se pojavljuje i iščezava iz horizonta kardinalnih umetnosti upravo prateći preplitanje i borbu starih i novih tendencija. U krajnjem, za filozofiju XVIII veka igra, pre svega balet, ipak ostaje u nekoj vrsti senke: igra se razumeva kao umetnost koja poseduje veliki potencijal, ali koja još uvek nije dovoljno istražena. Pod uticajem Batea, na primer, Luj d Kauzak (Louis de Cahusac) u Enciklopediji objavljuje nekoliko članaka o baletu u sasvim pozitivnom svetlu, a čak je i Didro (D. Diderot) smatrao da umetnost baleta potrebuje filozofa koji bi mogao da osvetli njen smisao i da je učini teorijski razgovetnijom (ChazinBennahum, 2007: 93). Navedeni primeri, prema našem mišljenju, ukazuju upravo na problem kojim smo se i mi u radu bavili: iako prihvaćena kao vredna i važna umetnost, igra ipak izostaje iz filozofskih razmatranja. Ova činjenica za prosvetiteljstvo XVIII veka čini igru problematičnom, jer u nedostatku jasnih i razumskih određenja igre naše iskustvo sa njom ostaje prepušteno sumnjivoj maglini iracionalnosti i imaginacije. Otuda je jedino moguće rešenje ovog paradoksa nada u buduće teorijsko rasvetljavanje igre, $u$ još jedno pokoravanje iracionalnog svetlošću razuma.

Igra, međutim, za takav projekat očigledno predstavlja naročit izazov. Pomenuti Didroov komentar može se uzeti i kao svojevrsni poziv na izgradnju 
jedne estetike igre, ali ona, kako smo videli, bitno izostaje. Tek estetika XX veka će postepeno i polako razvijati ovu mogućnost, delom i usled podsticaja koji dolaze od samih umetnika, uključujući tu i pojačanu svest o odsustvu estetike igre. Zanimljiv primer tog profila predstavljaju radovi S. Frejli (S. H. Fraleigh), autorke koja se bitno oslanja na fenomenološku misao, te $u$ nizu studija razvija jednu fenomenološku estetiku igre. Njeno razumevanje igre možda može da ilustruje i fundamentalni problem iskivanja jedne estetike igre, jer, kako kaže Frejlijeva: „Igrati po sebi ne znači zabavljati niti stvarati umetnost. Pre je u pitanju borba da se pronađe glas za narativno sopstvo; još više, da se suočimo sa sobom onako kako se suočavamo sa drugima i sa svetom - imaginativno" [prev. U. P.] (Fraleigh, 2004: 2).

\section{Una Popović}

\section{AESTHETICS OF DANCE - WHY NOT?}

\section{Summary}

The aim of this paper is to re-examine the question of dance as an art form. Namely, in the history of western philosophy and aesthetics there can scarcely be found examples of philosophical research dedicated to the art of dance. Therefore, we can speak of specific absence of dance and aesthetics of dance in the history of philosophy. Although the concept of dance plays a very prominent role in some philosophies, the art of dance is evidently neglected. The starting point of discovering the reasons that lead to such a situation is an $18^{\text {th }}$-century concept of art. The concept of art in the $18^{\text {th }}$ century is dissolved from its connections with science and knowledge, which in consequence made it possible for a new understanding of art to be formed. The analysis in the paper examines two specific forms of such change, the first one belonging to the project of Enlightenment and the other one marking arts as closely connected to the concept of beauty. Both proposed inclusion and exclusion of specific arts in the corpus of cardinal arts, the first one excluding and the other one including dance. Therefore, the result of this research is given in terms of pointing out to the criterion of this inclusion and exclusion as a question of knowledge, i.e. the question in which manner and how much should experience of art be considered as knowledgebearing. The absence of aesthetics of dance, therefore, can be traced to the tendency of modern aesthetics to envisage arts in terms of non-aesthetical problems of knowledge.

Key words: philosophy, aesthetics of dance, art, ballet, knowledge 


\section{LITERATURA:}

Batteux, Ch. (2015). The Fine Arts Reduced to a Single Principle. Oxford: Oxford University Press.

Burt, R. (2006). Judson Dance Theater: Performative Traces. London: Routledge.

Caroll, N. (1992). Theatre, Dance, and Theory: A Philosophical Narrative. Dance Chronicle, 3, 317-331.

Chazin-Bennahum, J. (2007). Jean-Georges Noverre: dance and reform. U: Kant, M. (ed.) (2007). The Cambridge Companion to Ballet. Cambridge: Cambridge University Press. 87-97.

Dalamber, Ž. R. (1995). Uvodna rasprava $u$ Enciklopediju. Beograd: Kultura.

Fraleigh, S. H. (2004). Dancing Identity. Metaphysics in Motion. Pittsburgh: University of Pittsburgh Press.

Kristeller, P. O. (1951). The Modern System of the Arts: A Study in the History of Aesthetics Part I. Journal of the History of Ideas, 4, 496-527.

Lippincott, G. (1949). A Dancer's Note to Aestheticians. The Journal of Aesthetics and Art Criticism, 2, 97-105

Tatarkijevič, V. (1980). Istorija šest pojmova. Beograd: Nolit.

Sparshott, F. (1982). On the Question: "Why Do Philosophers Neglect the Aesthetics of the Dance?" Dance Research Journal, 1, 5-30.

Sparshott, F. (1983). The Missing Art of Dance. Dance Chronicle, 2, 164-183. Zurovac, M. (2016). Ideja estetike. Beograd: Službeni glasnik. 